\title{
Wide Area Networks for Teleradiology
}

\author{
Kirkman G. Baxter, Louis H. Wetzel, Mark D. Murphey, Stanton J. Rosenthal, John E. Haines, \\ Solomon Batritzky, Joseph F. Caresio, Arch W. Templeton, and Samuel J. Dwyer
}

\begin{abstract}
Teleradiology networks transmit digital radiographic images from one location to another. These networks are wide area networks. Teleradiology networks are used for diagnostic purposes and preview tasks. Wide area networks for teleradiology use public service switching. The use of fiber optics networks provide reduced costs and increased flexibility. An example is presented that compares the cost of teleradiology networks.

Copyright 1991 by W.B. Saunders Company
\end{abstract}

KEY WORDS; teleradiology, digital, WAN, networks, image, communications

$\mathbf{T}$ ELERADIOLOGY networks transmit digital radiographic images and consultative text from one radiographic service location to another. These digital networks connect sites for purposes of interpreting patient's images. Connected sites may be located in remote areas as well as health facilities having no full time radiology coverage. There are two types of teleradiology networks: high-resolution (diagnostic) and low-resolution (preview). Highresolution teleradiology networks may be used to integrate multihospital/clinic health care consortiums (HMOs), for emergency service coverage or to provide subspeciality interpretation. Low-resolution teleradiology networks may be used to preview acquired images at home on evenings or weekends to provide prompt advice to physicians in emergency rooms, intensive care units, or elsewhere in the hospital. The various digital image data array sizes to be transmitted are identified in Table 1.

A teleradiology system is a computer communications $^{1,2}$ wide area network ${ }^{3}$ (WAN). A teleradiology WAN extends over large distances and connects computers together with the capability of transmitting any of the digital image data identified in Table 1.

Sites wishing to join an existing teleradiology system are either already paying for radiology coverage services (in varying degrees) or want to acquire increased radiology coverage. If the existing radiology coverage is by contract services, then some of these funds can be shifted to support the teleradiology system. The hardware cost for a high-resolution system per site is
$\$ 239,000$ to $\$ 377,000$ (Tables 2 and 3 ). These costs will decrease as the number of purchased teleradiology systems grow. The communication costs will add additional expense of $12 \%$ to $30 \%$ per year depending on the type of digital service chosen. WAN communication costs were once the most expensive item in any computer communications network. However, these costs are decreasing as the extensive bandwidth of fiber optics networks becomes available. This article examines the issues and cost of digital communications for WAN teleradiology networks.

\section{TYPES OF WIDE AREA NETWORKS FOR TELERADIOLOGY}

There are three types of public digital service computer communication networks available. They are circuit switching, message switching, and packet switching.

\section{Circuit Switching}

In circuit switching, ${ }^{4}$ (Fig 1) a complete route of connected links from the source host computer to the receiving host computer is established before the initiation of transmission. These connected links remain "intact" and dedicated to this transmission until released by both the source and the receiver. In the same manner as the telephone network for voice communication, the route is established by a special signaling message that finds its way through the network from the source to receiver, seizing channel links in the route as it proceeds. Once the route is completed, a return signal is sent to the source to initial transmission of the image data. During transmission, the source and receiver have a circuit connecting them during the entire transmission. When transmission is completed, signaling on the

From the Department of Diagnostic Radiology, University of Kansas Medical Center, Kansas City, KS, and US Sprint, National Accounts Division, Atlanta, GA.

Address reprint requests to Kirkman G. Baxter, MD, Department of Diagnostic Radiology, University of Kansas Medical Center, Kansas City, KS 66103

Copyright o 1991 by W.B. Saunders Company

0897-1889/91;0401-0005\$03.00/0 
Table 1. Digital Image Array Sizes

\begin{tabular}{|c|c|c|c|}
\hline Modality & $\begin{array}{l}\text { Megabytes } \\
\text { Per Image }\end{array}$ & $\begin{array}{l}\text { Average No. of } \\
\text { Images Per } \\
\text { Exam }\end{array}$ & $\begin{array}{c}\text { Average No. of } \\
\text { Megabytes Per } \\
\text { Exam }\end{array}$ \\
\hline $\begin{array}{l}\text { CT } \\
512 \times 512 \times 12 \text { bits }\end{array}$ & 0.5 & 30 & 15 \\
\hline $\begin{array}{l}\text { MRI } \\
256 \times 256 \times 12 \text { bits }\end{array}$ & 0.13 & 50 & 6.5 \\
\hline $\begin{array}{l}\text { DSA } \\
1 \mathrm{~K} \times 1 \mathrm{~K} \times 8 \text { bits }\end{array}$ & 1.0 & 20 & 20 \\
\hline $\begin{array}{l}\text { Digital fluorography } \\
1 \mathrm{~K} \times 1 \mathrm{~K} \times 8 \text { bits }\end{array}$ & 1.0 & 15 & 15 \\
\hline $\begin{array}{l}\text { Ultrasound } \\
512 \times 512 \times 6 \text { bits }\end{array}$ & 0.25 & 36 & 9 \\
\hline $\begin{array}{l}\text { Nuclear medicine } \\
128 \times 128 \times 8 \text { bits }\end{array}$ & 0.016 & 26 & 0.416 \\
\hline $\begin{array}{l}\text { Computed radiography } \\
2 \mathrm{~K} \times 2 \mathrm{~K} \times 10 \text { bits }\end{array}$ & 8.0 & 4 & 32 \\
\hline $\begin{array}{l}\text { Digitized film } \\
2 \mathrm{~K} \times 2 \mathrm{~K} \times 12 \text { bits }\end{array}$ & 8.0 & 4 & 32 \\
\hline $\begin{array}{l}\text { Digitized film } \\
4 K \times 4 K \times 12 \text { bits }\end{array}$ & 32 & 4 & 128 \\
\hline
\end{tabular}

network disconnects the communication links used.

In Fig 1, the host computer at Site $\mathrm{A}$ is transmitting image data to Site $\mathrm{C}$. The WAN circuit switching network has selected the path shown for transmission. This path will be released by special signals when both the transmitting host and receiving host notify the WAN that transmission has been completed.

The simplest circuit switch is one which has $\mathrm{N}$-inputs and $\mathrm{M}$-outputs. This type of circuit switch is called a space division switch. ${ }^{5}$ At the intersection of each input and output is an element called a crosspoint (called crossbars in the telephone network). Advances in very large scale integrated (VLSI) technology permit from 256 to 1,024 crosspoints in a single chip. The individual crosspoints are capable of passing

Table 2. Hardware and Maintenance Costs for Each Site (A, B, and C)

\begin{tabular}{lr}
\hline \multicolumn{1}{c}{ Equipment Item } & Estimated Costs \\
\hline Laser film digitizer & $\$ 72,000$ \\
Interactive gray scale work- & \\
station & 38,000 \\
Host computer systern & 45,000 \\
Optical disc archiving & 23,000 \\
Network access controller & 18,000 \\
Maintenance costs (10\% per & \\
year of hardware costs) & 21,740 \\
Total & $\$ 217,740$ \\
\hline
\end{tabular}

digital signals with data rates from $100 \mathrm{M}$ bits per second to over $1 \mathrm{G}$ bits per second. Switching times are on the order of a few nanoseconds.

A second type of circuit switch is a time division switch. ${ }^{6}$ Bytes of data from $\mathrm{N}$-input channels are time multiplexed together, written sequentially into a semiconductor memory, and then by computer control are read out and demultiplexed to the correct output channel. VLSI technology permits a single silicon chip to provide 1,024 channel time division switches, where the individual channels are operating at $56 \mathrm{k}$ bits per second or $64 \mathrm{k}$ bits per seconds.

Most digital switching systems use a combination of space and time division switching. These systems provide digital services of $64 \mathrm{k}$ bits per second (or $56 \mathrm{k}$ bits per second), $1.5 \mathrm{M}$ bits per

Table 3. Hardware and Maintenance Costs for Academic Radiology Department

\begin{tabular}{lr}
\hline \multicolumn{1}{c}{ Equipment Item } & Estimated Costs \\
\hline Laser film digitizer & $\$ 72,000$ \\
Laser film printer & 78,000 \\
Host computer system & 55,000 \\
Optical disc archiving & 50,000 \\
Interactive gray scale worksta- & \\
$\quad$ tion & 70,000 \\
Network access controller & 18,000 \\
Maintenance costs (10\% per & \\
$\quad$ vear of hardware costs) & 34,300 \\
Total & $\$ 377,300$ \\
\hline
\end{tabular}


$\underline{\text { Site A }}$

$\underline{\text { Site B }}$

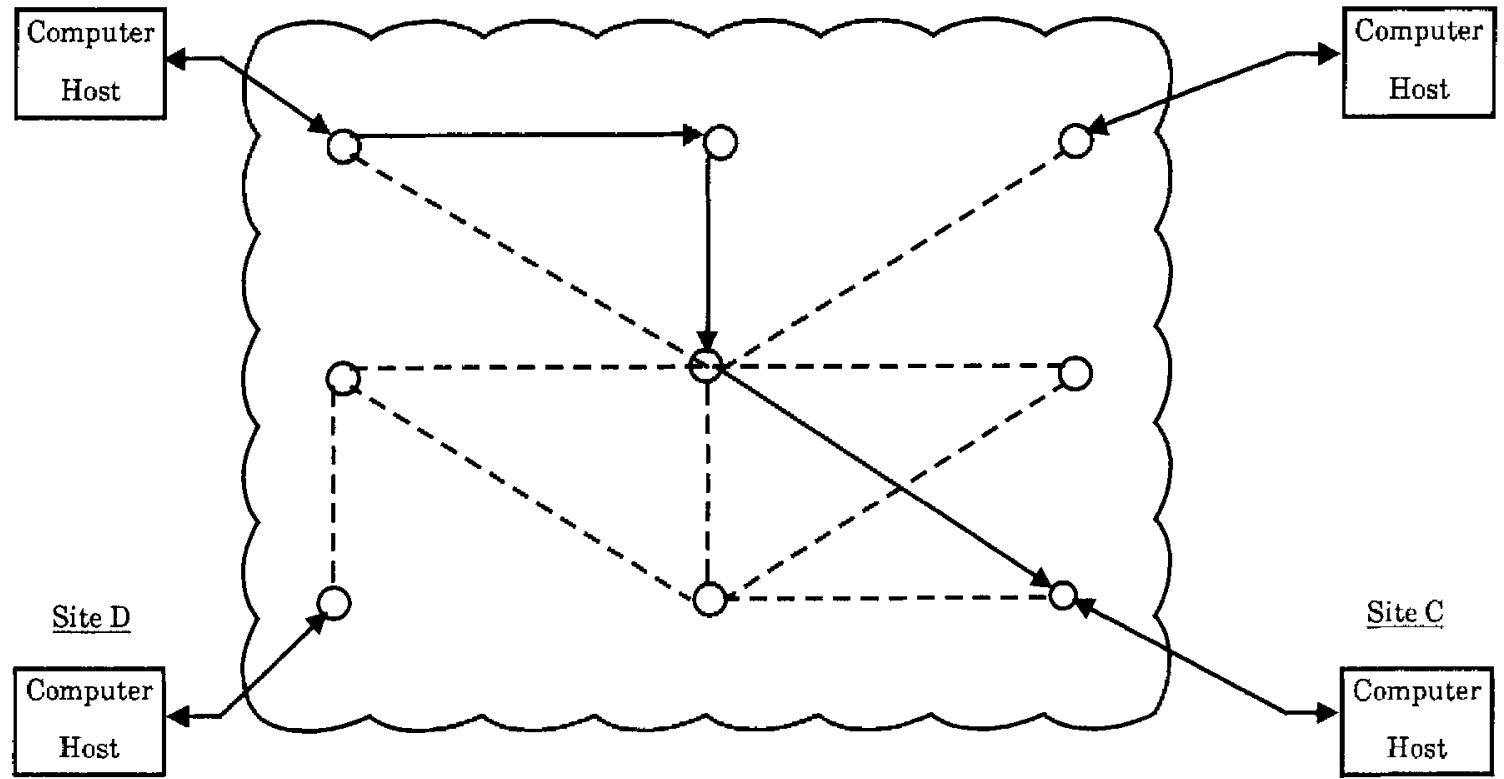

Fig 1. Circuit switching path from Site A to Site C. (-.., available paths: $O$, circuit switch; $\rightarrow$, circuit path selected $)$.

second (DS-1), and $45 \mathrm{M}$ bits per second (DS3). Time and space switching will permit digital services in the $\mathrm{G}$ bits per second range needed by fiber optics links.

\section{Message Switching}

One characteristic of computer-to-computer communication traffic is its "impulse" characteristic. Communications will consist of bursts of high-data rates followed by almost no data transmission. This implies that the average use of such communication paths will be low. In message switching (also called "store and forward" switching), ${ }^{7}$ there is no complete path established before starting transmission. Rather, the sending host computer will transmit a message to a switching center where it will be stored in a buffer. The stored message is kept in this buffer until the line to another switching center is available. When this line becomes available, the stored message is forwarded. This process is continued until the data arrives at the receiving host computer.

The advantage of this technique is that the link use is high, for one link may be involved in sending data to many host computers. The disadvantage is that long messages, such as digital images, require large storage buffers.
Furthermore, even if a link becomes available, a switching computer will not begin to transmit a message until it has been completely received.

\section{Packet Switching}

A packet switching network ${ }^{8-10}$ subdivides messages into small sizes, called packets, typically 1,024 bits. The message is transmitted packet-bypacket. Packet switching is a store-and-forward system where each packet is stored in buffers at the nodes on the network and then forwarded. Packets may follow different routes on the network and may arrive at the receiving host computer out of the sequence in which they were transmitted. For this reason, all packets are numbered so that they can be reassembled back into the original message.

Packet switching for messages of varying length provide the advantage of dynamic and fair allocation of the WAN's available bandwidth. The end-to-end transmission delay is smaller than that of message switching due to the division of the message into many smaller size packets and their transmission over multiple path lengths. Packet switching requires smaller storage at each node on the network than does message switching. Each packet includes information bits as well as additional bits 
called overhead information. The overhead bits are used to identify the destination of the packet, the source of the packet, user identification (for charging purposes), synchronization bits, and numbering bits (so as to properly reassemble the packets at the receiving host computer). Packet switching has the disadvantages that: packet switching requires the transmission of both information bits and overhead bits; and the packet switching hardware must "packetize" the messages, add overhead, depacketize and reassemble the message. However, due to the pipelining effect of packet transmission (multiple packets could be transmitted over multiple links), it is possible that packet switching will transmit a message in less time than that of message switching.

A local area network (LAN) ${ }^{11}$ is a packet switching network. The network consists of a single transmission medium that is shared by all nodes (multiaccess-broadcast). Network access is controlled by standard protocols, called media access control protocol. Packets are sent on the shared access medium. Any transmitting node's packet is heard by all other nodes (broadcasting). The packet switching function is accomplished by the sharing of a broadcast medium multiaccess protocol in which each receiving node accepts packets addressed to it. Signaling data rates on LAN's range from 1 to $100 \mathrm{M}$ bits per second.

\section{Integrated Services Digital Network (ISDN)}

The telephone network was developed as an analog transmission system. Replacement of the analog system by a digital system was broadened to include voice, data, and images. The advent of digital signal processing technology and computer systems, digital switches, and digital transmission is gradually replacing electromechanical switches and the analog facilities between them. Analog voice grade lines have been replaced with pulse code modulated (PCM) digital data voice grade channels, operating at data rates of $64 \mathrm{k}$ bits/second. A channel bank is used to convert 24 analog voice channels using analogto-digital conversion so as to provide a $\mathrm{T} 1$ service of $1.544 \mathrm{M}$ bits/second. A channel bank is required at each end of the communication link to convert the analog signal to digital data and digital signals to analog signals. Digital switches are being incorporated into the toll central offices, the local central offices, and digital signaling between these exchanges. An ISDN standard was established by the Consultative Committee for International Telephone and Telegraph (CCITT) for the functional standards of ISDN. To improve signaling speeds for the set-up and take-down communication links, a separate channel was established, called the common channel signaling network (Fig 2). As the evolution towards ISDN ${ }^{12}$ continues, local loops (which connects the local switching exchange to office/home) are being converted to digital links capable of transmitting two $64 \mathrm{k}$ bit/second channels (a B channel signals at $64 \mathrm{k}$ bit/second) and a D channel (a D channel signals at $16 \mathrm{k}$ bits/second) for signaling rates. Thus the basic rate access on the local loops is 2 $\mathrm{B}+\mathrm{D}$, or $128 \mathrm{k}$ bits/second plus $16 \mathrm{k}$ bits/ second for signaling. With ISDN, digital communications at $128 \mathrm{k}$ bits/second (plus D channel control signaling of $16 \mathrm{k}$ bits/second) is made available to homes and offices similar to the dial-up telephone capabilities. The primary rate access for digital links between exchanges is $1.544 \mathrm{M}$ bits/second (23 B + D channels).

The ISDN service will provide a wide range of applications in a public end-to-end digital communications network. An ISDN socket in the home or office would allow user connection of telephones, personal computers, display stations, and other devices. Existing circuit switched links, of which there are an abundance, provide the B channels of $64 \mathrm{k}$ bits/second. Separate packet switches are added to provide the $\mathrm{D}$ channel service. The D channel is mostly used for signaling on the network. The true ISDN will evolve so that the $B$ channels and $D$ channels will be merged into the same switching equipment.

The amount of data to be transmitted in a WAN teleradiology network requires higher bandwidths than $128 \mathrm{k}$ bits/second or $1.544 \mathrm{M}$ bits/second. The ISDN standard supports clear channels which use packet switching for supporting fast facsimile, compressed video, and highspeed data. These channels are: HO $(384 \mathrm{k}$ bits/second), H11 (1,536 k bits/second), and H12 (1,920 k bits/second). 


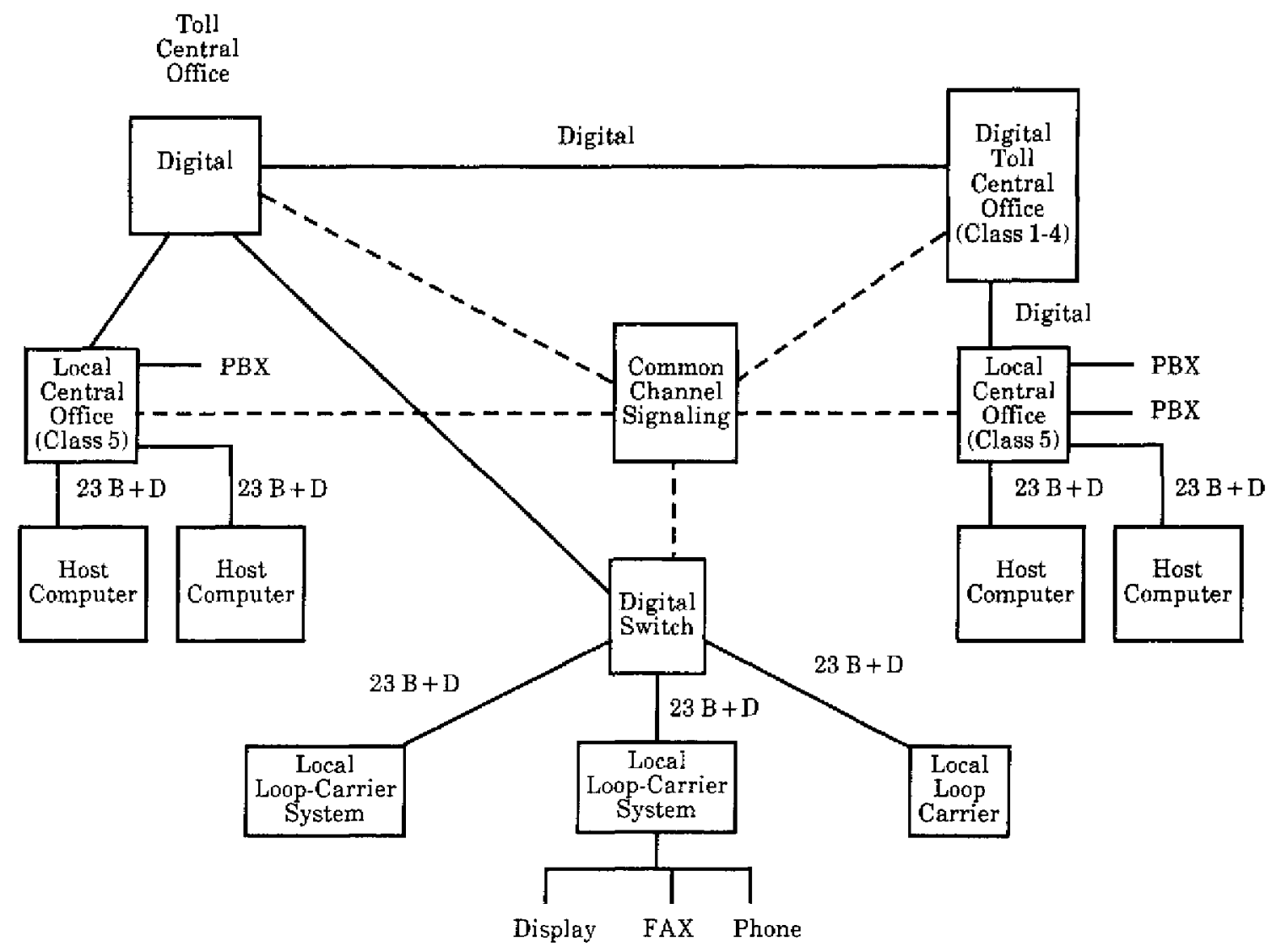

Fig 2. Architecture of the integrated services digital network.

\section{Fiber Optics Networks}

The primary application of optical transmission ${ }^{13}$ has been to extend the available bandwidth. This has resulted in increasing the transmission rates. Current systems have signaling rates that operate between $2 \mathrm{G}$ bits/second and $4 \mathrm{G}$ bits/second. The result of this higher transmission rate is that: the broad bandwidth services required for teleradiology applications are available; and the cost of using a $56 \mathrm{k}$ bits/ second (or $64 \mathrm{k} \mathrm{bit} / \mathrm{second}$ ) switched circuit is significantly reduced. The widespread deployment of fiber optics links has served to increase expectations for broadband services. Agreement was reached in CCITT on the definition of a broadband integrated services digital network (BISDN). ${ }^{5}$ This agreement for the Synchronous Digital Hierarchy (SDH) sets the transmission rates and signal formats for a digital broadband communications network. The transmission signal is called SDH-1 and has a rate of $156 \mathrm{M}$ bits/second. Interfaces to the users will be a packet-like protocol called Asynchronous Transfer Mode (ATM).

For long-haul communication networks, the Synchronous Optical Network (SONET) was recently adapted. ${ }^{14}$ The basic building block of the SONET signal hierarchy is called the Synchronous Transport Signal-Level 1. The STS-1 has a bit rate of $52 \mathrm{M}$ bits/second and is synchronous with a network synchronization source. The levels of the SONET signal hierarchy are shown in Table 4. Products are under development for the use of SONET protocols.

A SONET-type of WAN network architecture is illustrated in Fig 3. The OC-N refers to " $\mathrm{N}$ " increments of OC- 1 , where OC-1 is a 51.84 $\mathrm{M}$ bits/second optical carrier path. The SONET $\mathrm{D} / \mathrm{I}$ is a drop and insert multiplexer that functions as a digital switching system. The DS-3 digital service ( $45 \mathrm{M}$ bits/second) is the current digital primary interface for a fiber optic terminal (FOT). 
Table 4. Levels of the SONET Signal Hierarchy

\begin{tabular}{lc}
\hline $\begin{array}{c}\text { Level } \\
\text { (Optical Carrier) }\end{array}$ & $\begin{array}{c}\text { Line Rate } \\
\text { (M bits/second) }\end{array}$ \\
\hline OC-1 & 51.4 \\
OC-3 & 155.52 \\
OC-9 & 466.56 \\
OC-12 & 622.08 \\
OC-18 & 933.12 \\
OC-24 & $1,244.16$ \\
OC-36 & $1,866.24$ \\
OC-48 & $2,488.32$ \\
\hline
\end{tabular}

\section{COST ANALYSIS OF WAN TELERADIOLOGY NETWORKS}

The costs of implementing and operating a WAN teleradiology network depend upon the selected hardware, desired level of maintenance, and communication charges. Hardware and maintenance costs are fixed by the choice of a low-resolution or high-resolution type of teleradiology network. However, the communication costs of a WAN network vary depending on the type and number of images and the desired rate of transmission. We present the communication costs of a diagnostic type of WAN teleradiology network for a T1 carrier service (DS-1, point-to-point) and a switched multiple $56 \mathrm{k}$ bits/second service $(\mathrm{N} \times 56 \mathrm{k}$ bits/second $)$.

\section{Site Characteristics}

As an example, a proposed WAN connecting The University of Kansas Medical Center with three area hospitals is given. The academic radiology department and the three hospital sites have decided to work together and implement a WAN teleradiology network, which is a diagnostic type. The characteristics of each of the three hospital sites is shown in Table 5. Site $A$ is located 50 miles from the academic radiology department (Fig 4). They contract for onsite radiology services for one half day. It has been determined that Site $\mathrm{A}$ will transmit an average of 12 radiographic digitized films each working day of the week. Both Sites B and C have one full-time radiologist, transmitting 44 images per site, per day.

Sites $\mathrm{A}, \mathrm{B}$, and $\mathrm{C}$ are to be equipped with a host computer system, a laser film digitizer $(2 \mathrm{~K} \times 2 \mathrm{~K} \times 12$ bits), an interactive gray scale display workstation $(1 \mathrm{~K} \times 1 \mathrm{~K}$ display monitors), and a communication controller. The academic radiology department will have a host computer system, a laser film digitizer, an interactive gray scale display workstation (two monitors, each monitor $1 \mathrm{~K} \times 1 \mathrm{~K}$, and image display functions), a communication controller, and a laser film printer. All digitized radiographic films will be printed on the laser film printer ( $4 \mathrm{~K} \times 4 \mathrm{~K} \times 12$ bits) and displayed on the workstation. Each host computer system has memory and disc storage for archiving several days of image data. The hardware and maintenance costs for each site is shown in Tables 2 and 3.

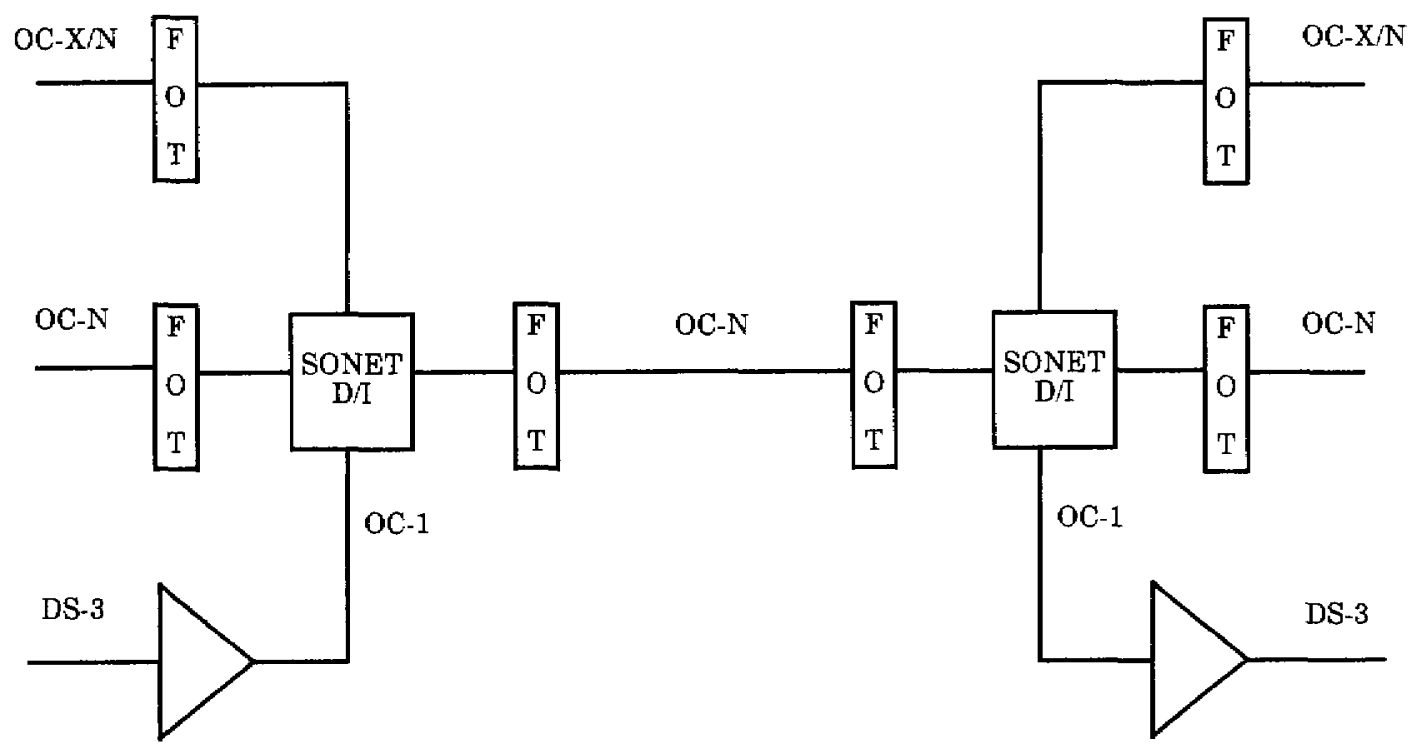

Fig 3. Architecture of the SONET fiber optics network. 
Table 5. Site Characteristics

\begin{tabular}{cccccc}
\hline Site & $\begin{array}{c}\text { Distance from } \\
\text { Academic } \\
\text { Radiology } \\
\text { Department }\end{array}$ & $\begin{array}{c}\text { No. of } \\
\text { Patient } \\
\text { Beds }\end{array}$ & $\begin{array}{c}\text { Radiology } \\
\text { Procedures } \\
\text { Per Day }\end{array}$ & $\begin{array}{c}\text { Radiology } \\
\text { Coverage }\end{array}$ & $\begin{array}{c}\text { Images to be } \\
\text { Transmitted } \\
\text { Per Day }\end{array}$ \\
\hline A & 50 miles & 50 & 30 & One-half day & 12 \\
B & 150 miles & 100 & 150 & 1 Full-time radiologist & 44 \\
C & 168 miles & 84 & 150 & 1 Full-time radiologist & 44 \\
\hline
\end{tabular}

After the first year, only the hardware maintenance costs will be incurred.

\section{Topology of WAN Teleradiology Network}

The users of the WAN teleradiology network have decided that they want the network links to be fiber optics, since fiber optics will offer high data throughput rates. However, due to the locations of the sites, it is not possible to provide the entire network with fiber optics links. Figure 4 shows the portions of the network that are fiber optics, the remainder being provided by the local carrier service. Site A is 24 miles from the interface to the fiber optics network. Site B is 62 miles from the interface, and Site $\mathrm{C}$ is 80 miles from the interface. The local carrier service will provide the digital service from each site to the point of entry onto the fiber optics network. The cost incurred for this service is called access charge. It has been decided to use a DS-1 service (1.544 M bits/second) for all links on the WAN teleradiology network.

\section{Communication Costs}

Communication costs are calculated for two types of DS-1 (1.544 M bits/second) service. The first type is a point-to-point T1 carrier service between each site and the academic radiology department. The second type of DS- 1 service is an $\mathrm{N} \times 56 \mathrm{k}$ bits/second service. For this service a communications controller is used which, depending on the selected value of $\mathrm{N}$, collects $\mathrm{N}-56 \mathrm{k}$ bits/second switched links and sends the image data in frames over multiple links. At the receiver, the frames are reassembled into the correct image data.

The T1 service (same as DS-1 rates) monthly charges are shown in Table 6. Each site is charged an access rate and a per mile charge. The monthly charges for this service are shown

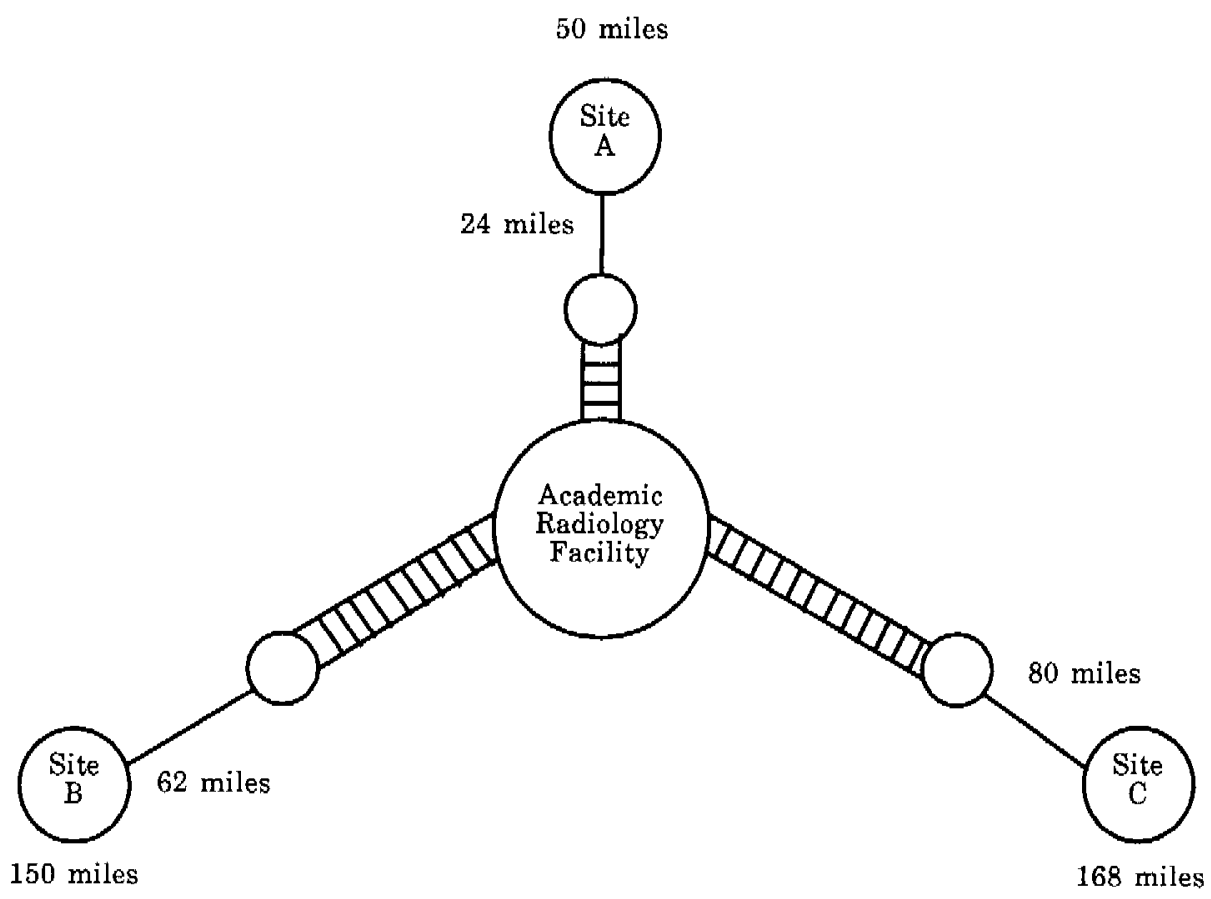

Fig 4. A WAN teleradiology network example for comparing costs. 
Table 6. Communication Costs for DS-1 Service

\begin{tabular}{cccccr}
\hline Site & $\begin{array}{c}\text { Megabits } \\
\text { Transmitted } \\
\text { Per Month* }\end{array}$ & $\begin{array}{c}\text { Site Access } \\
\text { Charges } \\
\text { Per Montht }\end{array}$ & $\begin{array}{c}\text { Site Access } \\
\text { Charges Per } \\
\text { Month for } \\
\text { Central Site }\end{array}$ & $\begin{array}{c}\text { T1 Carrier } \\
\text { Costs Per } \\
\text { Month\$ }\end{array}$ & $\begin{array}{c}\text { N } \times 56 \\
\text { k bits per Second } \\
\text { Costs Per } \\
\text { Month\| }\end{array}$ \\
\hline A & 12,079 & $\$ 1,700$ & $\$ 117$ & $\$ 4,195$ & $\$ 2,076$ \\
B & 44,290 & $\$ 354$ & $\$ 117$ & $\$ 3,519$ & $\$ 730$ \\
C & 44,290 & $\$ 3,500$ & $\$ 117$ & $\$ 6,786$ & $\$ 3,876$ \\
\hline
\end{tabular}

*Megabits per month $=20$ days per month $\times$ images per day $\times 50.33 \mathrm{M}$ bits/image. TDS- 1 access charges vary depending on available digital exchange equipment. fDS- 1 access charges at the academic radiology department is $\$ 350$, each site being charged $\$ 350 / 3$. $\S T 1$ carrier charges per month $=\$ 1,810+\$ 6.70$ per mile + access charges per month. $\| \mathrm{N} \times 56 \mathrm{k}$ bits per second charges per month a access charges per month + tariff per minute $\times 1$ rninute per 60 seconds $\times 1$ second $/ 56 \mathrm{k}$ bits $\times$ bits per month $\times 1.2$. Where 1.2 is protocol overhead and tariff is $\$ 0.06$ per minute.

in Table 5. T1 service is a point-to-point service for 24 hours per day. Accordingly, there is considerable under-use for this type of WAN teleradiology network. Access charges will vary depending on the available digital switching equipment in the region of each site.

The second type of service, $\mathrm{N} \times 56 \mathrm{k}$ bits/ second, takes advantage of the decreasing costs of switched $56 \mathrm{k}$ bits/second service. These costs are decreasing due to the increased availability of this type of service primarily because of the large amounts of fiber optics cable. The idea is that the site selects a value of $N(N=1$ is DS- 0 service; $\mathbf{N}=1,2, \ldots, 23$ ) and transmits at that rate. The communication controllers for this type of service are based on VLSI technology. The monthly costs for this type of service are shown in Table 5. This type of service may be referred to as a "casual user" service since the user pays for access charges and actual use charges. It should be noted that this type of service is not point-to-point. That is, each site can transmit to any other location with DS-1 access capabilities.

\section{DISCUSSION}

The cost comparisons of the two methods of WAN teleradiology network service show the extremes possible with digital service. The example teleradiology network (Fig 4) is a mixture of a long haul fiber optics network and a local carrier access. The access charges vary not so much by distance as by the availability of digital exchange equipment. As fiber optics cabling is enlarged to include each of the example sites, then the monthly access charges will decrease. In our example, as often happens, Site B has a low site access charge for T1 (or DS-1) service even though it is 150 miles distant from the academic radiology department. The local carrier is able to provide service to DS-1 access because the site is located in a region with a high concentration of digital exchange equipment.

The $\mathrm{T} 1$ service charges per month (Table 6) are for point-to-point, 24 hour per day use. It is clear that the megabits transmitted per month are an under-utilization of this type of digital service. Other functions, such as medical educational programs, could be shared and merged with the transmission of digital image data. A distinct disadvantage of the dedicated point-topoint WAN teleradiology network is its limited connectivity. To expand to other sites will require the installation of added point-to-point service.

The $\mathrm{N} \times 56 \mathrm{k}$ bits/second "casual user" type of service requires the same access charges as that of the T1 service. However, the user charges (cost per minute) are only for the time the line is actually used. It is clear that in our example (Table 6) the usage charges are minimal due to the small amount of data being transmitted. Hence, the $\mathrm{N} \times 56 \mathrm{k}$ bits/second scheme reflects mostly access charges. As the fiber optics cables become installed nearer each site, then the access charges for DS-1 service will approach $\$ 350$ per month.

It should be noted that the advantage of the $\mathrm{N} \times 56 \mathrm{k}$ bits/second switched service is that the user charges are independent of $\mathrm{N}$. Hence the user cost for $N=23$ is the same as the user cost for $N=1$. The reason is that the time of transmission for large N's is shorter. This exam- 
ple shows the many possible network protocols that are available due to the advancements in digital circuitry and the higher bandwidth from fiber optics networks. The one-time hardware cost to equip each site (Table 5) will decrease as the demand for WAN teleradiology networks increases.

Higher speed digital services, such as DS-3 service ( $45 \mathrm{M}$ bits/second) are available, but are difficult to acquire in rural areas. Access charges for this service will be much higher than those for DS-1 service (Table 6). However, as fiber optics networks are placed near each of the teleradiology sites, the access cost will decline. It is possible to implement the $\mathrm{N} \times 56 \mathrm{k}$ bits/ second controller scheme using DS-3 service. The OC-X SONET long-haul carrier will provide higher data rates for WAN teleradiology networks.

\section{REFERENCES}

1. Andrew $S$ Tanenbaum: Computer Networks. Englewood Cliffs, NJ, Prentice-Hall Inc., 1981

2. Dimitri Bertsekas, Robert Gallager: Data Networks. Englewood Cliffs, NJ, Prentice-Hall Inc., 1987

3. Chlamtac I, Franta WR: Rational, directions, and issues surrounding high speed networks. Proceedings of the IEEE 78:94-120, 1990

4. Joel $\mathrm{Jt} \mathrm{AE}$ : What is telecommunications circuit switching? Proceedings of the IEEE 65:1237-1253, 1977

5. Bethold JE: High Speed Integrated Electronics for Communication Systems. Proceedings of the IEEE 78:486511,1990

6. Tomita S, Yokimatsu KI, Mizuno T, et al: Some aspects of time-division data switch design. Proceedings of the 1EEE 65:1295-1304, 1977

7. Maxemchuk NF, Zarki ME: Routing and flow control in high-speed wide-area networks. Proceedings of the IEEE 78:204-221, 1990
8. Roberts LG: The evolution of packet switching. Proceedings of the IEEE 66(11):1307-1313, 1978

9. Kleinrock L: Principles and lessons in packet communications. Proceedings of the IEEE 66:1320-1329, 1978

10. Tobagi FA: Fast packet switch architectures for broadband integrated services digital networks. Procedings of the IEEE 78:133-167, 1990

11. William Stallings: Local Networks. 2nd edition, New York, NY, Macmillan Publishing Co. 1987

12. William Stallings: Integrated Services Digital Networks (ISDN), Tutorital, IEEE Computer Society Press, Los Angeles, CA, 1985

13. Tomlinson WJ, Brackett CA: Telecommunications appliçations of integrated optics and optoelectronics. Proceedings of the IEEE 75:1512-1523, 1987

14. Hac A, Mutlu HB: Synchronous optical network and broadband ISDN protocols. Computer 22:26-34, 1989 